\title{
Trapping a somatic endogenous retrovirus into a germline piRNA cluster immunizes the germline against further invasion
}

\author{
Céline Duc ${ }^{1,2+}$, Marianne Yoth ${ }^{1 \dagger}$, Silke Jensen ${ }^{1}$, Nolwenn Mouniée ${ }^{1}$, Casey M. Bergman ${ }^{3}$, Chantal Vaury ${ }^{1 *}$ and \\ Emilie Brasset $^{1 *}$ (D)
}

\begin{abstract}
Background: For species survival, the germline must faithfully transmit genetic information to the progeny. Transposable elements (TEs) constitute a significant threat to genome stability due to their mobility. In the metazoan germline, their mobilization is limited by a class of small RNAs called PIWl-interacting RNAs (piRNAs) produced by dedicated genomic loci called piRNA clusters. Although the piRNA pathway is an adaptive genomic immunity system, it remains unclear how the germline gains protection from a new transposon invasion.

Results: To address this question, we analyze Drosophila melanogaster lines harboring a deletion within flamenco, a major piRNA cluster specifically expressed in somatic follicular cells. This deletion leads to derepression of the retrotransposon ZAM in the somatic follicular cells and subsequent germline genome invasion. In this mutant line, we identify de novo production of sense and antisense ZAM-derived piRNAs that display a germinal molecular signature. These piRNAs originated from a new ZAM insertion into a germline dual-strand piRNA cluster and silence ZAM expression specifically in germ cells. Finally, we find that ZAM trapping in a germinal piRNA cluster is a frequent event that occurs early during the isolation of the mutant line.

Conclusions: Transposons can hijack the host developmental process to propagate whenever their silencing is lost. Here, we show that the germline can protect itself by trapping invading somatic-specific TEs into germline piRNA clusters. This is the first demonstration of "auto-immunization" of a germline endangered by mobilization of a surrounding somatic TE.
\end{abstract}

Keywords: Transposable elements, piRNAs, piRNA cluster, Genome stability, Inheritance, Drosophila, Germline

\section{Background}

Germ cells are the only cell type within multicellular organisms that can transfer genetic and epigenetic material to the offspring. Due to their capacity to move, transposable elements (TEs), a major component of eukaryotic genomes, constitute a significant threat to the germline genome integrity [1-3]. Indeed, their mobilization could lead to gene disruption or chromosomal rearrangements. To limit TE mobilization in the germline, a class of small RNAs of 23 to 29 nucleotides (nt) in length, called PIWI-interacting RNA (piRNAs), are expressed in the reproductive tissue and

\footnotetext{
*Correspondence: chantal.vaury@uca.fr; emilie.brasset@uca.fr ${ }^{\dagger}$ Céline Duc and Marianne Yoth contributed equally to this work. 'GReD, Université Clermont Auvergne, CNRS, INSERM, Faculté de Médecine, 63000 Clermont-Ferrand, France

Full list of author information is available at the end of the article
}

silence TE activity via homology-dependent mechanisms [4-7].

The piRNA pathway has been extensively studied in the Drosophila melanogaster ovary that comprises about 16 ovarioles, each of which contains a succession of follicles composed of germline and somatic follicular cells [8]. In D. melanogaster, piRNAs are encoded by dedicated genomic loci that are called piRNA clusters [9] These clusters are composed of full length or truncated TEs that define the repertoire of elements that are recognized and silenced by the piRNA machinery. Two classes of piRNA clusters have been defined on the basis of their transcriptional properties: (i) unidirectional or uni-strand and (ii) bidirectional or dual-strand piRNA clusters [9]. Unidirectional clusters are expressed predominantly in somatic follicular cells of ovaries, while

(c) The Author(s). 2019 Open Access This article is distributed under the terms of the Creative Commons Attribution 4.0 International License (http://creativecommons.org/licenses/by/4.0/), which permits unrestricted use, distribution, and 
bidirectional clusters are transcribed in germline cells. Therefore, TEs are silenced in both cell types by piRNAs via different mechanisms $[10,11]$. Transcription of piRNA clusters produces long piRNA precursors that are diced into piRNAs. In germline cells, these piRNAs are loaded on the Piwi protein to form a complex that triggers TE transcriptional silencing [12]. In addition to Piwi, two other PIWI-family proteins, Aub and Ago3, participate in the post-transcriptional control of TEs. They act to amplify the piRNA pool by a mechanism called the ping-pong cycle $[9,13]$. Moreover, Aub- and Ago3-bound piRNAs are deposited in the embryo to ensure the re-initiation of piRNA clusters and efficient TE control in the offspring germline [14-16]. In somatic follicular cells, whose genome does not contribute to the next generation but which could be the origin of transposon invasion, a simplified version of the piRNA pathway is active because only the Piwi protein is expressed $[17,18]$. The tissue-specific expression of piRNA clusters, which contain different TE sequences, suggests a tissue-specific regulation of certain classes of elements. For instance, flamenco is the best characterized piRNA cluster predominantly expressed in somatic follicular cells. The flamenco locus is a uni-strand cluster that extends over more than $180 \mathrm{~kb}$ and is located in the pericentromeric heterochomatin of $D$. melanogaster $\mathrm{X}$ chromosome [19-21]. Most TEs inserted in flamenco belong to the long terminal repeat (LTR) group of retrotransposons and are oriented opposite to the cluster transcription direction. Across the entire spectrum of transposons described in flamenco, maternally deposited piRNAs targeting some TEs, such as ZAM or gypsy, are underrepresented in the embryonic piRNA pool [17]. This suggests that piRNAs matching these TEs are not produced by any germline piRNA cluster and that they originate from the main somatic piRNA cluster, flamenco. Thus, these TEs should be exclusively silenced in somatic follicular cells. In the absence of efficient silencing of these TEs in somatic follicular cells, the oocyte genome is exposed to internal threats. Indeed, when the silencing of $Z A M$ or gypsy is released in somatic follicular cells, these (and potentially other) retrovirus-like TEs can infect germline cells [22, 23]. Therefore, the stability of the germline genome requires efficient silencing of TEs also in somatic follicular cells.

The piRNA pathway has often been compared to an adaptive immune system, because it conveys the memory of previous transposon invasions by storing TE sequence information within piRNA clusters [17]. This model leads to several major questions. Particularly, it is not known whether some TE classes are regulated only in specific tissues and whether and how germ cells can counteract TE invasion from the surrounding somatic follicular cells. To gain insights into these issues, we used $D$. melanogaster lines in which $Z A M$ expression is either silenced (i.e., "stable," $\mathrm{w}^{\mathrm{IR6}}$ line) or derepressed (i.e., "unstable," RevI-H2 also named RevI in [21]). The RevI-H2 line was derived from the $\mathrm{w}^{\mathrm{IR} 6}$ line after Pmediated mutagenesis [24, 25] and displays a large deletion of the proximal (i.e., the region closest to the centromere) part of flamenco corresponding to the region containing its only $Z A M$ insertion [26]. This suggests a tight correlation between the presence of $Z A M$ in the flamenco locus and the repression of all functional genomic copies of $Z A M$ in the somatic follicular cells [26].

Here, we found that in the $\mathrm{w}^{\mathrm{IR} 6}$ ovaries, $Z A M$ was silenced only in follicular cells with an absence of a germline-specific silencing mechanism. Conversely, in the RevI-H2 line, ZAM was derepressed in somatic follicular cells and silenced in the germline following its rapid trapping into a germline piRNA cluster. This represents an efficient mechanism of protection against TE invasion from the surrounding somatic tissues.

\section{Results \\ ZAM is silenced in a tissue-specific manner}

Previous studies have reported that distinct tissuespecific piRNA populations are expressed in the germline and in somatic follicular cells [17]. This suggests a tissue-specific repression of TEs. Here, we used ZAM to monitor the germline capacity to repress TEs for which no germline piRNA is produced. $Z A M$ is a prototypic somatic TE [17, 27] and ZAM-derived piRNAs are highly depleted in the early embryonic piRNA population that mirrors the germline piRNA population [17]. To monitor $Z A M$ repression, we generated a sensor transgene that expresses the GFP reporter gene under the control of an inducible Upstream Activation Sequence promoter (UASp) and harbors a ZAM fragment in its 3'UTR (pGFP-ZAM) (Fig. 1a). Transgene expression analysis in both somatic and germline cells using the actin-Gal4 driver showed that pGFP-ZAM was completely silenced in somatic cells (Fig. 1b). This indicated that $Z A M$-derived piRNAs, which are produced by flamenco in these cells, targeted the transgene and efficiently guided its silencing. Conversely, in germline cells, its expression was not inhibited, as shown by the strong GFP signal (Fig. 1b). This showed that ZAM silencing is specific to somatic follicular cells suggesting that it is mediated by the somatic flamenco cluster, as shown by genetic evidence $[21,28]$ and that there are no ZAM-derived piRNAs from any germline piRNA cluster.

\section{ZAM-derived piRNAs are produced in the germline in response to follicular cell instability}

$Z A M$ silencing release in somatic follicular cells could expose the oocyte genome to internal threats arising from the surrounding follicular cells. To analyze how 


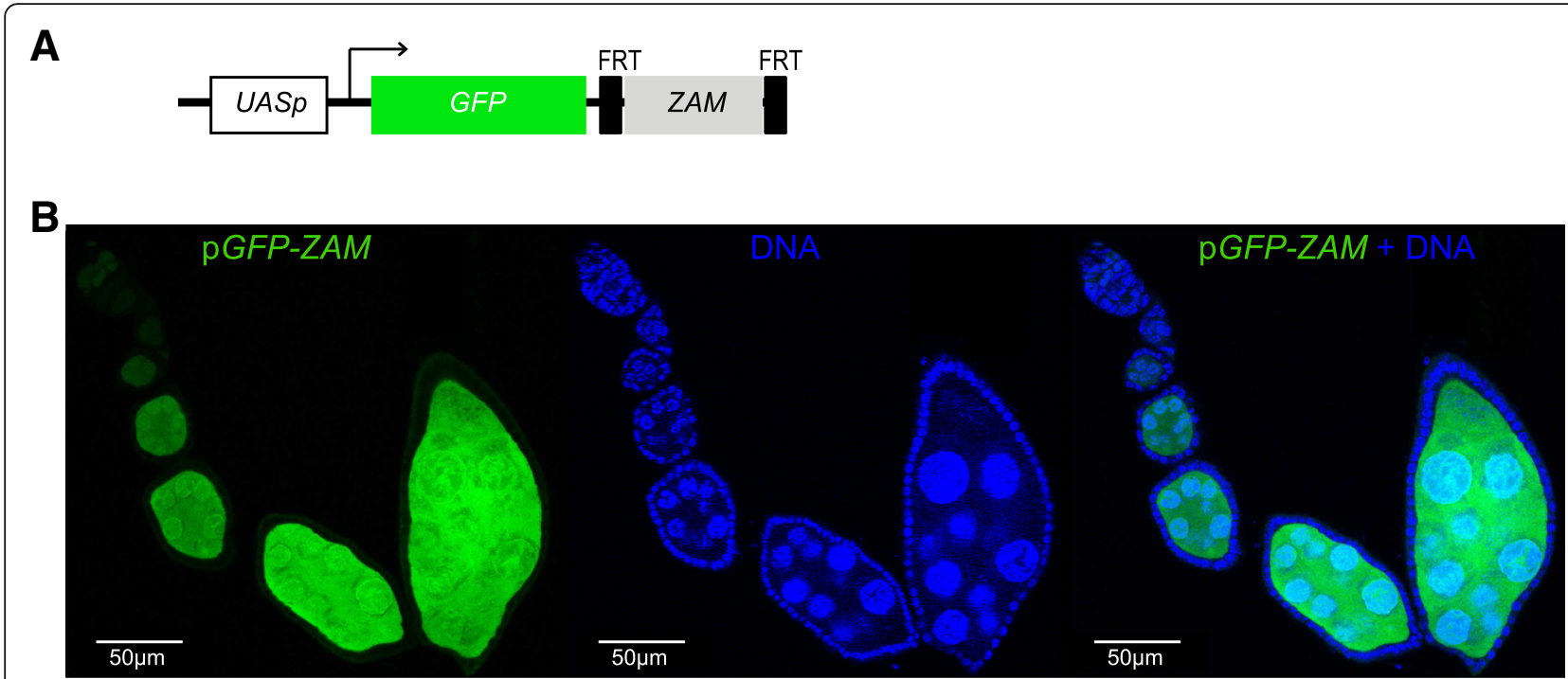

Fig. 1 The ZAM sensor transgene is not repressed in the germline of D. melanogaster ovaries. a Structure of the pGFP-ZAM sensor transgene. The UASp promoter contains the Gal4 target sequence upstream of the GFP reporter gene fused to $467 \mathrm{bp}$ of the ZAM env gene (light grey box, sense orientation). The ZAM sequence is flanked by two FRT sites. The arrow indicates the transcription initiation site. $\mathbf{b}$ Confocal images of ovarioles after GFP (green, left) and DNA (blue, middle) staining. Ovarioles were from the progeny of a cross between $w^{1118}$ females and males harboring the pGFPZAM transgene driven by the actin-Gal4 driver. Merged images for GFP and DNA labeling are displayed on the right

the germline may protect itself against TE mobilization from the surrounding follicular cells, we used RevI-H2 flies harboring a deletion in the proximal part of flamenco [21] that eliminates the region in which $Z A M$ is inserted [26] (Additional file 1: Figure S1A), but does not affect germline development. In contrast, as the flamenco piRNA cluster is the main source of piRNAs (78\%) produced in somatic follicular cells (Fig. 2a), other mutations affecting flamenco expression, such as flamKG and flamBG, lead to disruption of piRNA production, but also to impairment of ovarian germline stem cell differentiation and division, thus preventing further analysis of how the germline might respond to any TE mobilization initiated in the surrounding follicular cells [28]. In addition, the close relationship between the parental $\mathrm{w}^{\mathrm{IR} 6}$ and derived RevI-H2 allowed us to closely control for the genetic background.

To determine whether the flamenco deletion in RevI$\mathrm{H} 2$ was associated with changes in piRNA production at this locus, we sequenced and compared ovarian small RNAs from the RevI-H2 line and the parental $\mathrm{w}^{\mathrm{IR} 6}$ line. This highlighted the complete loss of piRNAs produced at the deleted locus in RevI-H2 samples compared with the $w^{\text {IR6 }}$ control line (Fig. 2b). Conversely, the global production of piRNAs uniquely mapping to the flamenco locus upstream of the deletion was not affected by the deletion (1,238 and 1,239 Reads Per Million for the RevI-H2 and $\mathrm{w}^{\mathrm{IR} 6}$ samples, respectively) (Fig. $2 \mathrm{~b}$ and Additional file 1: Figure S1B).

As expected from earlier studies, in the $w^{\text {IR6 }}$ control line, $88 \%$ of $Z A M$-derived piRNAs mapped to piRNA clusters [9] (without mismatch) and $86 \%$ of them mapped the flamenco locus (Fig. 3a). Detailed analysis showed that piRNAs were predominantly antisense to the $Z A M$ sequence (Fig. $3 \mathrm{~b}$ ), in agreement with $Z A M$ insertion in the antisense orientation relative to flamenco transcription orientation (Additional file 1: Figure S1A) [26]. Moreover, $90 \%$ of ZAM-derived piRNAs displayed a uridine bias at the $5^{\prime}$ end, a feature of mature primary piRNAs (Fig. 3c). As $Z A M$ is absent from the RevI-H2 flamenco locus and is derepressed in somatic follicular cells of RevI-H2 ovaries [21], we hypothesized that production of $Z A M$-derived piRNAs would be abolished in RevI-H2 ovaries. However, sequencing of ovarian small RNAs revealed that antisense $Z A M$-derived piRNAs were considerably increased (three times) in RevI-H2 ovaries compared with $\mathrm{w}^{\mathrm{IR6}}$ ovaries (Fig. 3d). Moreover, many more $Z A M$-derived sense piRNAs were produced in RevI-H2 than in $w^{\text {IR6 }}$ ovaries (Fig. 3e). To identify the cellular origin of these $Z A M$-derived piRNAs, we performed a nucleotide profile analysis. We identified a bias for uracil at the first position (1 $\mathrm{U})$ and for adenine at the tenth position (10A) (Fig. 3f). This is a typical feature of piRNAs generated by the ping-pong amplification mechanism that occurs exclusively in germline cells. We then checked the ping-pong signature (i.e., a 10nucleotide overlap between sense and antisense pairs of ZAM-derived piRNAs) $[9,13]$ and found significant enrichment for this signature in the RevI-H2 line, but not in the parental $w^{\mathrm{IR} 6}$ line (Fig. $3 \mathrm{~g}$ ). Moreover, in RevI-H2 samples, $34 \%$ of the ZAM-derived piRNAs possessed ping-pong partners (PPP), i.e., piRNAs which 
A

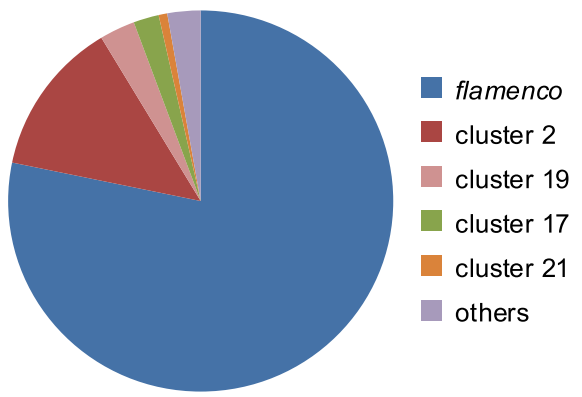

somatic follicular piRNAs
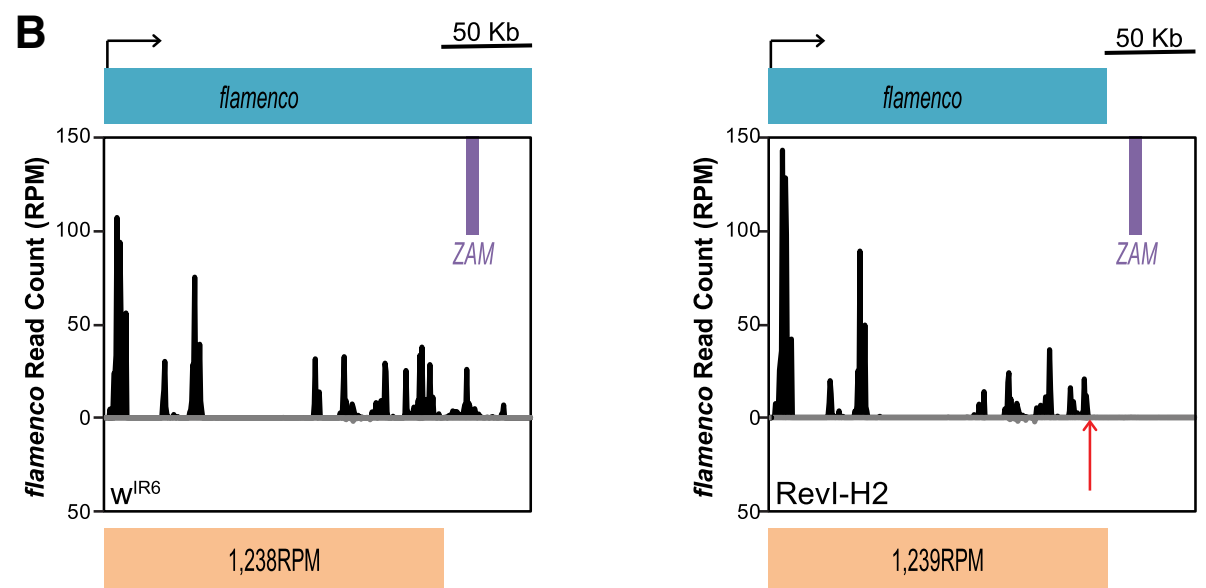

Fig. 2 Deletion of some TE fragments in flamenco does not impair the global piRNA production from this piRNA cluster. a Pie chart showing the proportion of unique piRNAs that map to each of the 142 piRNA clusters in ovarian somatic sheath cells (no mismatch allowed, piRNA clusters defined as in [9]). b Density profile of unique piRNAs from the $w^{\text {IR6 }}$ (left) and Revl-H2 (right) lines that map to the flamenco piRNA cluster. Sense and antisense reads are presented in black and grey, respectively. Almost no antisense reads map to the flamenco piRNA cluster. ZAM location in flamenco is displayed by a purple box. The flamenco deletion distal break-point in Revl-H2 [26] (Additional file 1: Figure S1B) is indicated by a red arrow and the sense of transcription by a black arrow. The count of piRNA reads per million (RPM) mapping the non-deleted region of flamenco, indicated below, does not differ between $\mathrm{w}^{\mathrm{IR} 6}$ and Revl-H2

present a 10-nt $5^{\prime}$-overlap between sense and antisense ZAM-derived piRNAs (Fig. $3 \mathrm{~h}$ ). In addition, they harbored the typical $10 \mathrm{~A}$ and $1 \mathrm{U}$ bias (Fig. 3i, Additional file 1: Figure S2A-B). This abundant production of sense and antisense $Z A M$-derived piRNAs and the ping-pong signature enrichment were similar to the results obtained for piRNAs derived from Burdock, a typical target of the germline piRNA pathway (Additional file 1: Figure $\mathrm{S} 2 \mathrm{C}-\mathrm{H}$ ). Altogether, these findings strongly suggested a germinal origin of the ZAM-derived piRNAs produced in the RevI-H2 line.

Aub and Ago3, the two main proteins involved in piRNA production through the ping-pong mechanism, were expressed only in the germline in both $\mathrm{w}^{\mathrm{IR} 6}$ and RevI-H2 ovaries (Additional file 1: Figure S3A-B). This excluded a ping-pong-mediated ectopic production of $Z A M$-derived piRNAs in somatic cells of RevI-H2 ovaries. Moreover, we found that these new ZAM-derived piRNAs in RevI-H2 were maternally deposited in early embryos (Additional file 1: Figure S3C-D) and possessed the same characteristics as those produced in adult ovaries (Additional file 1: Figure S3E-G). Taken together, our data strongly suggested that these $Z A M$-derived piRNAs were produced in the germline of RevI-H2 ovaries. This is intriguing because $Z A M$ has been classified as a somatic TE, only expressed in somatic cells $[17,21]$.

To monitor the silencing potential of $Z A M$-derived piRNAs produced in the germline of the RevI-H2 ovaries, we followed the GFP expression of the pGFP-ZAM sensor transgene in the presence of the actin-Gal4 driver. In $w^{\text {IR6 }}$ control ovaries, the transgene was completely silenced in somatic cells and strongly expressed in germline cells (Fig. 3j) as observed for $\mathrm{w}^{1118}$ (Fig. 1b). Conversely, in RevI-H2 ovaries, the transgene was silenced in the germline and strongly expressed in somatic cells. When the ZAM sequence was excised upon recombination between the flanking FRTs giving rise to a pGFP transgene lacking targets for ZAM piRNAs, GFP 
A

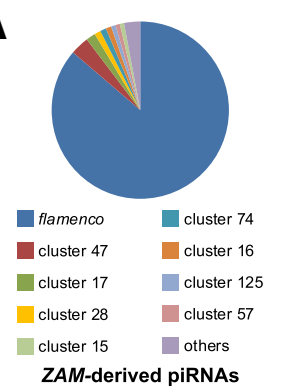

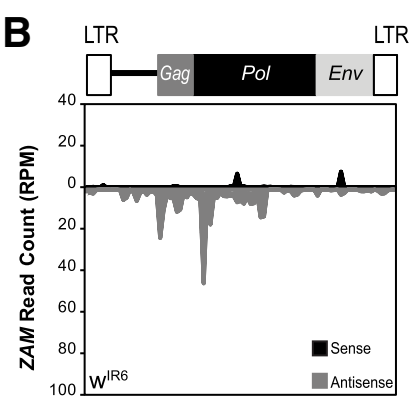

E

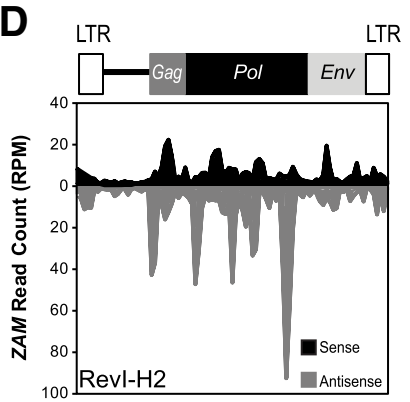

G
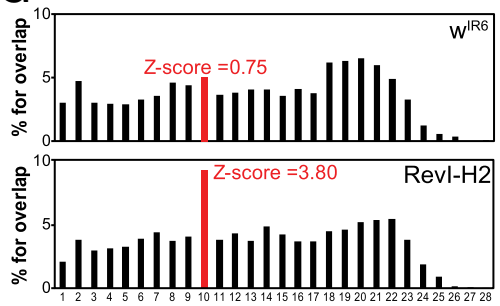

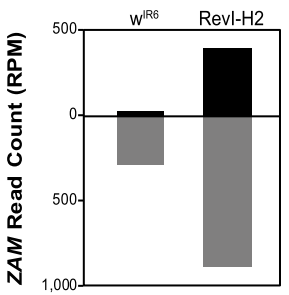

H

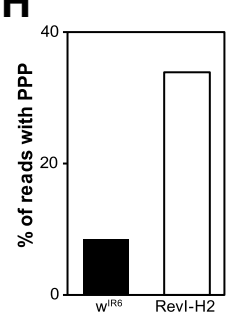

C

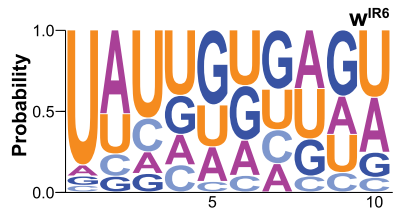

F
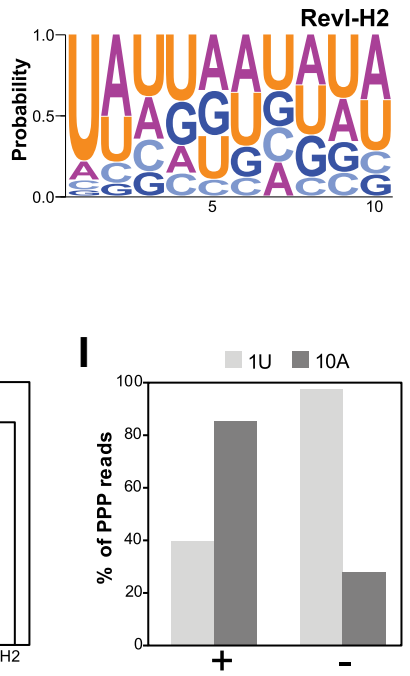

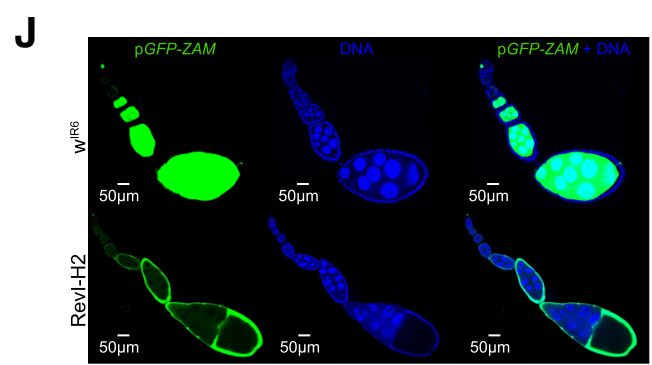

Fig. 3 De novo production of functional ZAM-derived piRNAs in the germline of the Revl-H2 line. a Pie chart summarizing the proportion of ZAM-derived piRNAs (allowing up to 3 mismatches) that map to the 142 piRNA clusters in w ${ }^{\mathbb{R} 6}$ (no mismatch allowed, piRNA clusters defined as in [9]). b Density profile of ZAM-derived piRNAs along the $8.4 \mathrm{~kb}$ ZAM sequence in $w^{\mathrm{IR} 6}$ ovaries (allowing up to 3 mismatches). Sense and antisense reads are represented in black and grey, respectively. ZAM organization is displayed above the profile. LTR, long terminal repeats. $\mathbf{c}$ Logo of nucleotide bias for the first ten positions in ZAM-derived piRNAs produced in $w^{\mathbb{I R} 6}$ ovaries. The nucleotide height represents its relative frequency at that position. $\mathbf{d}$ Density profile of ZAM-derived piRNAs along the ZAM sequence produced in Revl-H2 ovaries (allowing up to 3 mismatches). Sense and antisense reads are represented in black and grey, respectively. e Bar diagram showing the total amount of ZAM-derived piRNAs produced in $w^{\text {IR6 }}$ and Revl-H2 ovaries, quantified from the profiles shown in $\mathbf{b}$ and $\mathbf{c}$, respectively. $\mathbf{f} L$ Logo of nucleotide bias for the first ten positions of ZAM-derived piRNAs produced in Revl-H2 ovaries. $\mathbf{g}$ Histogram showing the percentage of 5'-overlap between sense and antisense ZAM-derived piRNAs (23-29 nt) in w w $^{\mathrm{IR}}$ (top) and Revl-H2 (bottom) ovaries. The proportion of 10-nt overlapping pairs is in red, and the Z-score is indicated. $\mathbf{h}$ Bar diagram indicating the percentage of ZAM-derived piRNAs with ping-pong partners (PPP) in the $\mathrm{w}^{\mathbb{R} 6}$ and Revl-H2 lines. $\mathbf{i}$ Analysis of nucleotide bias for sense (+) and antisense (-) ZAM-derived piRNAs with PPP in Revl-H2 ovaries. The percentage of PPP with a uridine at position $1(1 \mathrm{U})$ and with an adenosine at position $10(10 \mathrm{~A})$ is shown. $\mathbf{j}$ Confocal images of ovarioles after GFP (green, left panels) and DNA (blue, middle panels) staining. Ovarioles were from the progeny of a cross between $w^{\mathrm{IR} 6}$ or Revl-H2 females and males carrying the pGFP-ZAM sensor transgene driven by actin-Gal4. Right panels, merged images of GFP and DNA labeling 
is strongly expressed in RevI-H2 and $w^{\mathrm{IR} 6}$ somatic and germline cells indicating that the ZAM fragment in the fusion transcript is responsible for GFP repression (Additional file 1: Figure $\mathrm{S} 3 \mathrm{H}$ ). To confirm that the pGFP$Z A M$ transgene silencing is piRNA mediated, we knocked down the germline expression of Aub or AGO3 and monitored GFP expression. We showed that the pGFP-ZAM transgene is strongly expressed in the germline of both $A u b-\mathrm{KD}$ and $A G O 3-\mathrm{KD}$ (Additional file 1: Figure S3I-J), confirming that the transgene is silenced by a piRNA-mediated mechanism. These results indicated that RevI-H2 germline cells produce $Z A M$-derived piRNAs that efficiently guide sensor silencing. Conversely, GFP is strongly expressed in RevI-H2 somatic follicular cells that do not produce $Z A M$-derived piRNAs due to the deletion of the proximal part of flamenco.

Taken together, we concluded that in RevI-H2 ovaries, functional $Z A M$-derived piRNAs are produced in the germline from a new $Z A M$ insertion somewhere outside the deleted region of the flamenco cluster.

\section{ZAM transposed into a pre-existing germline piRNA cluster}

$Z A M$-derived piRNA production in the RevI-H2 line could be explained by insertion of a new copy of $Z A M$ into a pre-existing germline piRNA cluster or by the de novo creation of a piRNA cluster in the germline induced by a new $Z A M$ insertion. To discriminate between these hypotheses, we studied the activity of this putative piRNA cluster in the progeny obtained by crossing $w^{\text {IR6 }}$ and RevI-H2 flies. Since germline piRNAs are maternally deposited in the embryo and this transgenerational piRNA inheritance triggers piRNA biogenesis in the progeny $[15,16]$, we predicted that if $Z A M$-derived piRNAs in RevI-H2 arose from a de novo-formed piRNA cluster, repression operated by this cluster should only be observed when the locus is inherited from the mother. Conversely, if the germline repression of ZAM is due to an insertion in a pre-existing piRNA cluster, then piRNA produced by this cluster should induce repression when inherited from either parent (Additional file 1: Figure S4A).

We named ZMD (for maternal deposition of ZAM-derived piRNAs) the progeny obtained by crossing a RevI$\mathrm{H} 2$ female and a control male and NZMD (no maternal deposition of $Z A M$-derived piRNAs) the progeny of a RevI-H2 male and a control female. In both crosses, the control line was the line harboring the pGFP-ZAM transgene, the expression of which is driven in germline cells by the nanos-Gal4 driver in the $\mathrm{w}^{1118}$ background. In both ZMD and NZMD progenies, the sensor transgene was completely silenced in germline cells, as shown by immunofluorescence and western blot analysis
(Fig. $4 \mathrm{a}-\mathrm{c}$ ). This finding suggested that the unknown piRNA cluster that can silence the sensor transgene in the germline does not need maternal deposition of $Z A M$-derived piRNAs to be active. Indeed, the maternal deposition of the general piRNA population, required to activate piRNA clusters in the progeny, was sufficient for the production of $Z A M$-derived piRNAs in the progeny. Therefore, we concluded that the $Z A M$-derived piRNAs produced in the RevI-H2 germline arose from a $Z A M$ sequence inserted into a pre-existing germline cluster. To further analyze the sensor silencing and to rule out the possibility that the transgene has become a piRNA cluster by itself, we sequenced and compared ovarian small RNAs from the ZMD progeny (Fig. 4d, right panel) and from a control line in which the pGFP-ZAM transgene is expressed in the germline (in the $\mathrm{w}^{\text {IR6 }}$ genetic background: Fig. 4d, left panel, and Additional file 1: Figure S4B-C). The results indicated that the sensor transgene was not a de novo piRNA cluster because the upstream GFP sequence produced very few piRNAs, while a significant amount of piRNAs mapped to the $Z A M$ fragment in the ZMD progeny (Fig. 4d, right panel). These data suggested the presence of a new ZAM insertion in a pre-existing germline piRNA cluster.

To genetically map this germline piRNA cluster that produces $Z A M$-derived piRNAs in the germline, we isolated each chromosome of the RevI-H2 line and established three lines harboring (i) the $\mathrm{X}$ chromosome from RevI-H2 ( $\mathrm{X}^{\text {RevI-H2}}$; II; III and referred as $\mathrm{X}^{\text {RevI-H2}}$ ); (ii) the autosomal chromosome II from RevI-H2 (X; II RevI-H2 ; III and referred as $\mathrm{II}^{\text {RevI-H2}}$ ); or (iii) the autosomal chromosome III from RevI-H2 (X; II; III ${ }^{\text {RevI-H2 }}$ and referred as $\mathrm{III}^{\text {RevI-H2}}$ ). It should be noted that the $\mathrm{II}^{\text {RevI-H2 }}$ and III ${ }^{\text {RevI-H2 }}$ lines carry a wild-type flamenco locus, while the $\mathrm{X}^{\mathrm{RevI}-\mathrm{H} 2}$ line harbors the flamenco deletion present in RevI-H2. To identify which chromosome was required for germline production of $Z A M$-derived piRNAs, we assessed the GFP expression of the $p G F P$ $Z A M$ sensor transgene driven by nanos-Gal4 in each line. We found that the transgene was silenced in the germline of the $\mathrm{X}^{\text {RevI-H2 }}$ line, like in RevI-H2 (Additional file 1: Figure S4D-E). Conversely, it was expressed in the $\mathrm{II}^{\text {RevI-H2}}$ and III ${ }^{\text {Rev I-H2 }}$ germlines (Additional file 1: Figure S4D-E). This indicates that in RevI-H2 ovaries, $Z A M$-derived piRNAs are produced from a germline piRNA cluster localized on the X chromosome.

We sought to identify the precise genomic location of this new $Z A M$ insertion in a germline piRNA cluster localized on the $\mathrm{X}$ chromosome by performing whole genome sequencing of RevI-H2. We first searched for new $Z A M$ insertions in euchromatin within the RevI-H2 genome using the McClintock pipeline [29], which identified seven $Z A M$ insertions on the $\mathrm{X}$-chromosome, including the known $Z A M$ insertion in the white locus at $\mathrm{X}: 23,474$, 

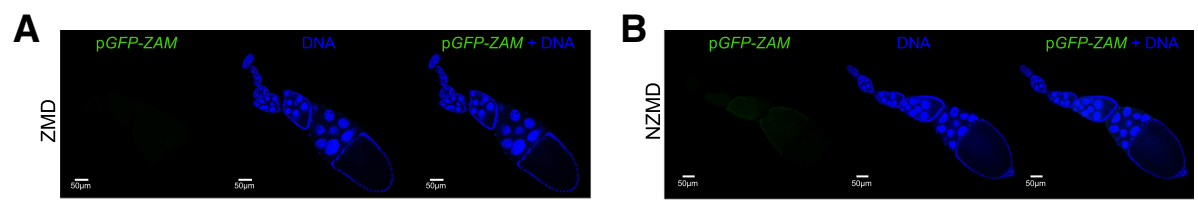

C
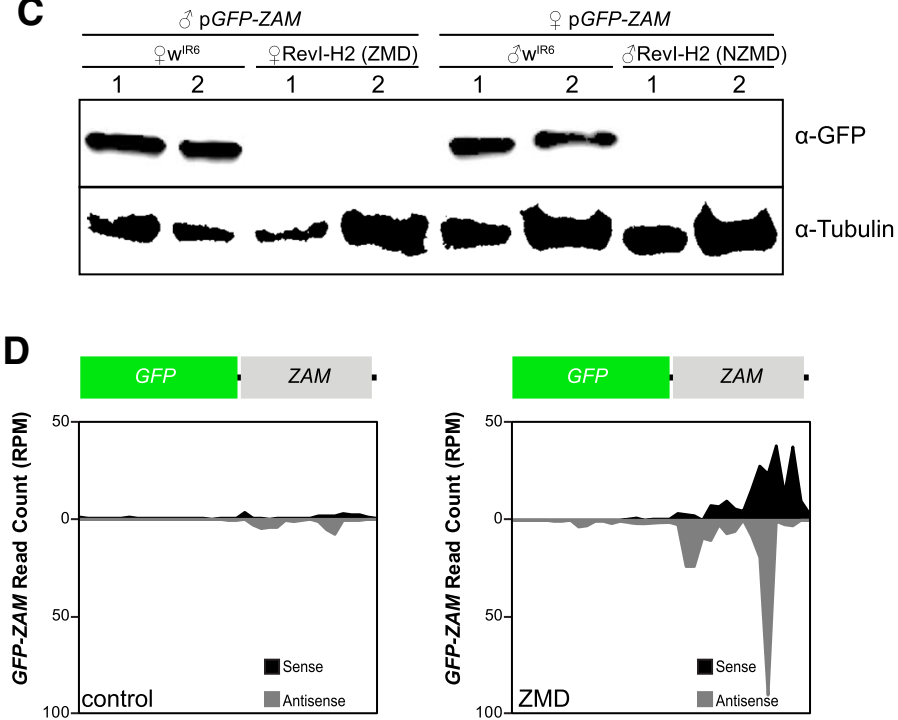

Fig. 4 ZAM-derived piRNAs are produced from a pre-existing germline piRNA cluster in Revl-H2 ovaries. a-b Confocal images of ovarioles after GFP (green, left panels) and DNA (blue, middle panels) staining. Merged images of the GFP and DNA signals are displayed on the right. Ovarioles were from the progeny of a cross between Revl-H2 females and control males (ZAM maternal deposition, ZMD) in a and from a cross between Revl-H2 males and control females (No ZAM maternal deposition, NZMD) in $\mathbf{b}$. In both crosses, the pGFP-ZAM line in which ZAM expression is driven in germline cells by a nanos-Gal4 driver was the control line. $\mathbf{c}$ Western blotting of proteins extracted from ovaries of progenies of crosses between $w^{I R 6}$ or Revl-H2 and the same control line as in $\mathbf{a}$ and $\mathbf{b}$. The lines used for the crosses are indicated above. Proteins were from two biological replicates (1 and 2) prepared from 5 pairs of ovaries; a-tubulin was used as loading control. $\mathbf{d}$ Density profile of piRNAs mapping along the GFP-ZAM transgene sequence (allowing up to 3 mismatches). Sense and antisense reads are in black and grey, respectively. The profiles are for crosses between $w^{I R 6}$ (left, control) or Revl-H2 (right, ZMD) females and control males harboring the pGFP-ZAM transgene

449..23,513,109. None of these X-chromosome insertions are found in known piRNA clusters. Since the component methods in McClintock do not efficiently detect new TE insertions within repetitive regions, TE nests or piRNA clusters, we used a complementary approach to identify chimeric reads containing both $Z A M$ sequence and genomic sequence, which were not uniquely mappable on the reference genome. Using this approach, we identified a new $Z A M$ insertion that mapped to a $\mathrm{R} 1$ element sequence found at multiple locations within cluster 9 [30], a dual-strand piRNA cluster located next to the $\mathrm{X}$ chromosome centromere (Additional file 1: Figure S4F). Analysis of paired-end reads followed by PCR and sequencing in RevI-H2 (Additional file 1: Figure S4G) localized the $Z A M$ insertion to one of the three possible sites within this piRNA cluster spanning the interval X: $23,474,449 . .23,513,109$. A previous inverse PCR study in RevI-H2 also detected this ZAM insertion but could not map it to a specific genomic location [24]. PCR analysis confirmed that this ZAM insertion is absent from the stable lines $\mathrm{w}^{\mathrm{IR} 6}$, ISO1A, and $\mathrm{w}^{1118}$ (Additional file 1: Figure S4H).

These analyses demonstrated that the RevI-H2 line possesses a $Z A M$ insertion in a pre-existing germline piRNA cluster located on the $\mathrm{X}$ chromosome.

\section{Analysis of TEs lost with the flamenco deletion in Revl-H2 reveals various patterns of piRNA production}

Besides $Z A M$, several other transposons are contained within the flamenco deletion in RevI-H2: Adoxo, Gedeo, Idefix, Phidippo, Pifo, Uxumo, and Vatovio (Additional file 1: Figure S1A). To verify whether the genomic deletion also affected the epigenetic regulation of other transposons, we analyzed the piRNA population produced by RevI-H2 ovaries against these different elements. We focused our analysis on Phidippo and Pifo because they appeared to be mainly silenced by flamenco. Indeed, in the control line $\mathrm{w}^{\mathrm{IR} 6}$, Phidippo- and Pifo-derived piRNAs did not harbor a ping-pong signature (Fig. 5a) and were mainly antisense (Fig. 5b, c). 
A
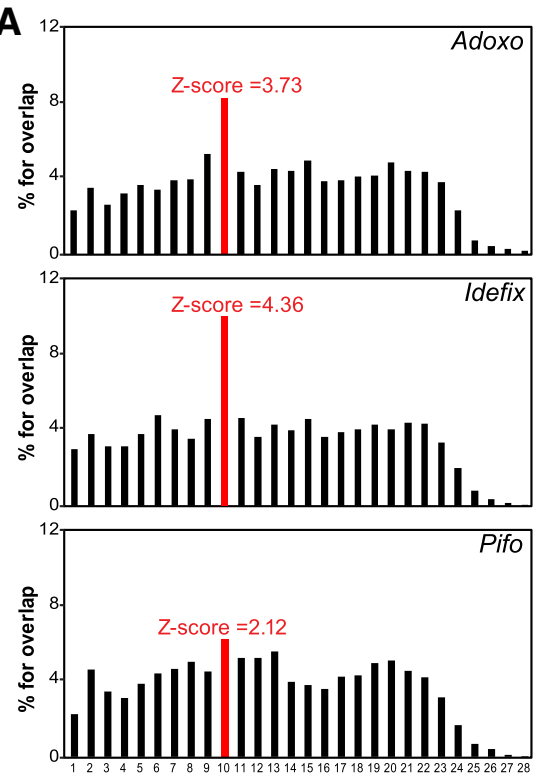
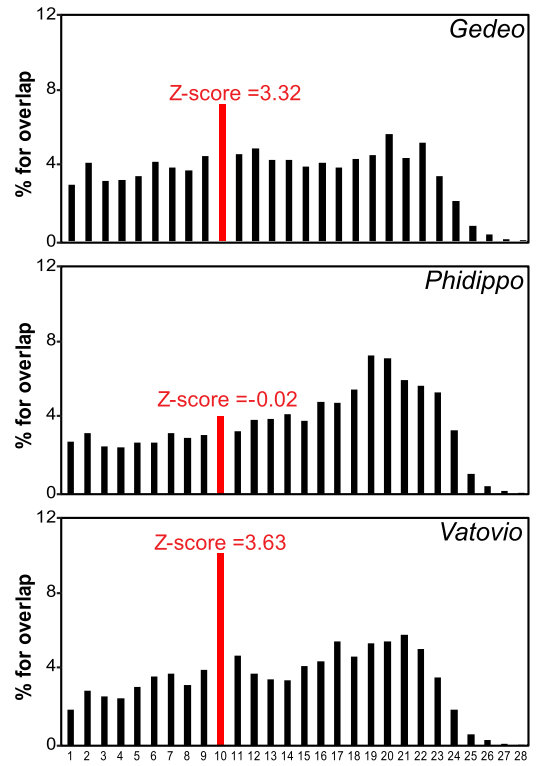

B
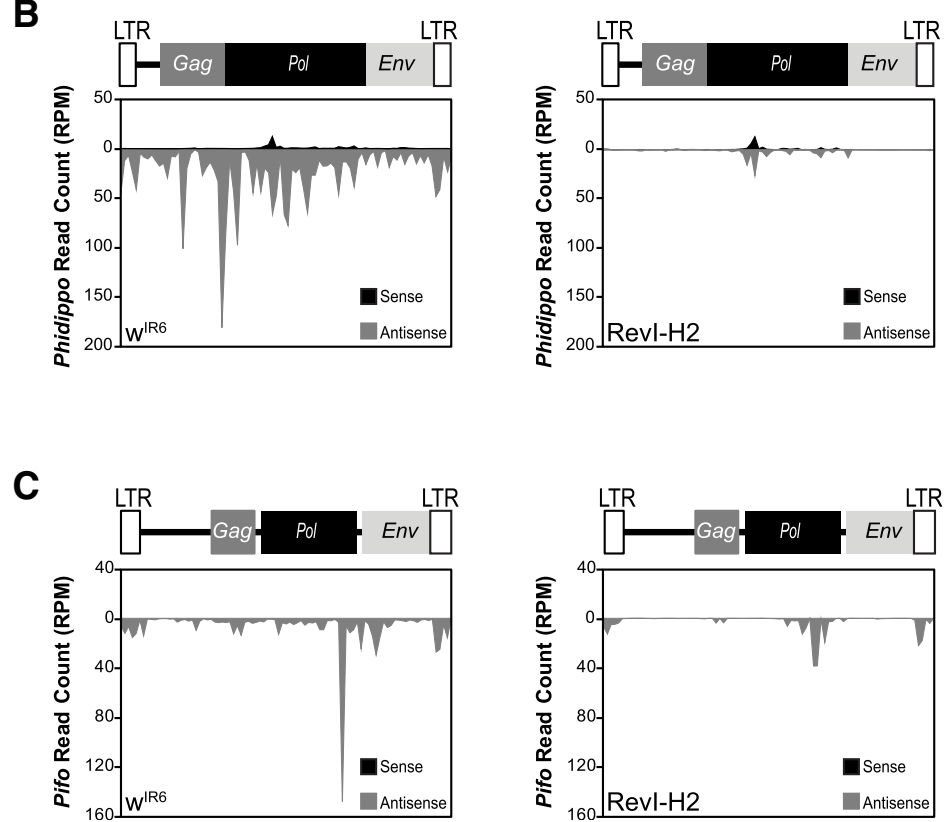

Fig. 5 Production of Phidippo- and Pifo-derived piRNAs is lost in Revl-H2. a Histogram for the percentage of 5'-overlaps between sense and antisense Adoxo-, Gedeo-, Idefix-, Phidippo-, Pifo-, and Vatovio-derived piRNAs (23-29 nt) in w ${ }^{\mathrm{IR6}}$ ovaries. The peak in red defines the 10-nt-overlapping pairs, and the Zscore is indicated. b, c Density profile of Phidippo- (b) and Pifo- (c) derived piRNAs along the $7.3 \mathrm{~kb}$ Philippo sequence and $7.7 \mathrm{~kb}$ Pifo sequence, respectively, in $\mathbf{W}^{\text {IR6 }}$ (left) and Revl-H2 (right) ovaries (using all piRNAs mapped to the corresponding TE allowing up to 3 mismatches). Sense and antisense reads are represented in black and grey, respectively. The organization of the two TEs is displayed above their respective profile

Conversely, Adoxo-, Gedeo-, Idefix-, and Vatovio-derived piRNAs displayed a ping-pong signature (Fig. 5a, Additional file 1: Figure S5A). Moreover, 37\% of Phidippoand $54 \%$ of Pifo-derived piRNAs that mapped to piRNA clusters [9] mapped flamenco, and 21\% of Phidippoderived piRNAs mapped cluster 17 (Additional file 1: Figure S5B-C). Notably, cluster 17 has been proposed to be part of the flamenco cluster [26], raising the percentage of Phidippo-mapping piRNAs that map to the extended flamenco to $58 \%$.

In the RevI-H2 line, production of Phidippo- and Pifoderived piRNAs was almost abolished (Fig. 5b, c), differently from what observed for $Z A M$-derived piRNAs (Fig. 3d). In contrast to $Z A M$, which must have an active copy outside the flamenco region that gave rise to the new ZAM insertions in RevI-H2 (such as the reference 
genome copies at 2R:1,808,663..1,817,084 and $3 \mathrm{~L}: 24,168$, 844..24,176,114), no additional active copy of Phidippo or Pifo has been identified in the reference genome, besides the one in the flamenco locus. This indicated that the Pifo- and Phidippo-derived piRNAs are produced almost exclusively by flamenco and that in the absence of additional functional copies, these TEs could not invade the genome, differently from ZAM.

\section{Transposition of ZAM in a germline piRNA cluster is an early event}

The Rev line was first identified two decades ago [24] based on a phenotypic reversion of the mutated eye phenotype of $\mathrm{w}^{\mathrm{IR} 6}$ flies due to a de novo $Z A M$ insertion upstream of the white gene. A series of homozygous RevI lines (RevI-H1, RevI-H2, and RevI-H3) were then derived from the initial Rev line. Several secondary mutations affecting eye color were recovered from the initial RevI-H2 line, and new lines were successively isolated and called RevII ([25]; see [31] for further description). To further trace when the germline acquired the potential to silence $Z A M$, we sought to determine when the $Z A M$ insertion into a germline piRNA cluster occurred. We sequenced ovarian small RNAs from RevII-7 (which was derived 20 years ago from RevI-H2). Detailed analysis of ZAM-derived piRNAs in RevII-7 samples showed that $Z A M$-derived sense and antisense piRNAs were produced to an extent similar to what observed in the RevI-H2 line (Fig. 6a). These piRNAs displayed the typical ping-pong signature: a bias for $1 \mathrm{U}$ and 10A (Fig. 6b) and the enrichment of 10-nt 5 '-overlaps (Fig. 6c). Moreover, 25\% of the ZAM-derived piRNAs had a PPP with the typical $10 \mathrm{~A}$ and $1 \mathrm{U}$ bias (for the sense and antisense PPPs, respectively) (Additional file 1: Figure S6A-F). We concluded that the $Z A M$ insertion event into a germline piRNA cluster occurred before the RevII lines were derived from the RevI-H2 line.

Thus, the ZAM insertion event may have occurred very early when the three RevI lines (RevI-H1, RevI-H2, and RevI-H3) were established from the initial Rev line. Sequencing of small RNAs from RevI-H3 ovaries and analysis of $Z A M$-derived piRNAs showed again the production of sense and antisense piRNAs, but with a high bias for sense piRNAs (Fig. 6d), differently from what observed in the RevII-7 and RevI-H2 lines (Figs. 6a and 3d). The bias for $1 \mathrm{U}$ and 10A (Fig. 6e) and the enrichment of the 10-nt 5 -overlap were also present in the RevI-H3 line (Fig. 6f), but to a smaller extent than in the RevI-H2 and RevII-7 lines. In RevI-H3 samples, 20\% of the ZAM-derived piRNAs possessed a PPP with the typical $10 \mathrm{~A}$ and $1 \mathrm{U}$ bias (Additional file 1: Figure S6BF). These results suggested that the RevI-H3 line, which was independently established at the same time as RevI$\mathrm{H} 2$, also carries a $Z A M$ insertion in a germline piRNA cluster. However, the differences observed for ZAM-derived piRNAs produced in RevI-H2 and RevI-H3 suggested that there may be secondary changes to the piRNA cluster 9 or that $Z A M$ inserted into another piRNA cluster in RevI-H3 different from the one identified in RevI-H2.

In addition to providing context about the timing of the germline invasion, the RevII-7 and RevI-H3 allowed us to determine the conservation of ZAM repression over time in independent stocks. To monitor the efficiency of the various $Z A M$-derived piRNAs produced in the germline of the RevII-7 and RevI-H3 lines, we followed the GFP expression of the pGFP-ZAM sensor transgene. Like for the RevI-H2 line, the transgene was completely silenced in germline cells and strongly expressed in somatic cells in both RevII-7 and RevI-H3 (Additional file 1: Figure S6G).

To conclude, analysis of the various Rev mutant lines suggested that $Z A M$ transposition into a germline piRNA cluster (leading to de novo $Z A M$-derived piRNAs production) is an early and frequent event essential for germline protection against invasion by mobile elements from the surrounding somatic tissue.

\section{Discussion}

TEs have colonized the genome of all living organisms. To ensure their vertical transmission and amplification in multicellular organisms, mobile element transposition has to take place in germ cells. In turn, germ cells have developed specialized strategies to protect the integrity of their genome and thus the species continuity. Using the prototypic somatic element ZAM from D. melanogaster, we discovered that the germline can rapidly evolve to control the activity of TEs after invasion from the surrounding somatic tissues by trapping copies of the invading element into germline piRNA clusters. This ensures the production of piRNAs against the invading $\mathrm{TE}$ and germline genome protection.

\section{The germline can adapt to the threat of active transposon invasion from surrounding somatic tissues}

The flamenco locus is a master piRNA cluster, expressed only in somatic follicular cells that do not transfer any genetic information to the progeny. It produces somatic piRNAs characterized by the absence of the ping-pong signature. The very efficient TE silencing in somatic tissue by flamenco protects the germline genome against invasion by somatic TEs. The expression pattern of TEderived piRNAs suggests that several TEs (gtwin, gypsy, Tabor, gypsy5, gypsy10, and ZAM) are almost exclusively controlled by flamenco-derived piRNAs [17]. In this study, we demonstrated that in control ovaries, $Z A M$ is repressed exclusively in somatic follicular cells and no $Z A M$-derived piRNAs are produced in the germline, 

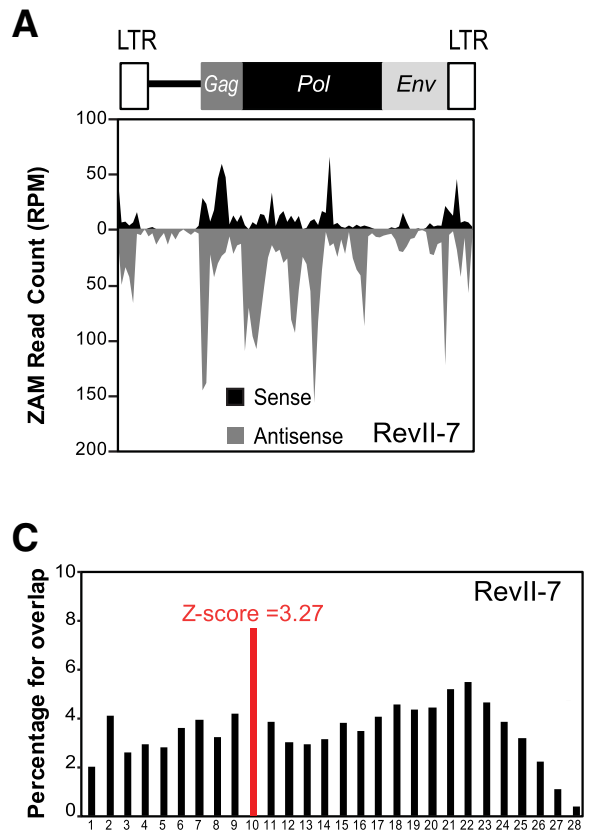

E

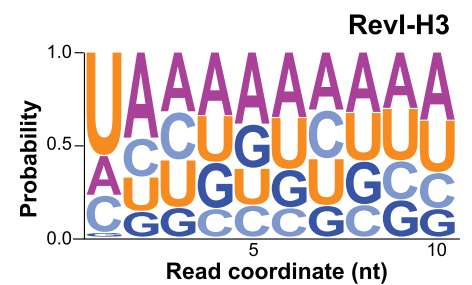

Revll-7

B

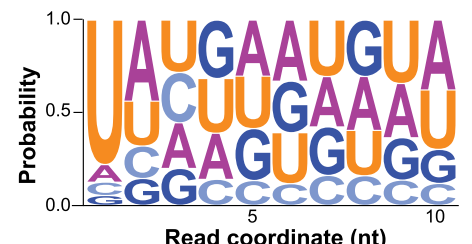

D

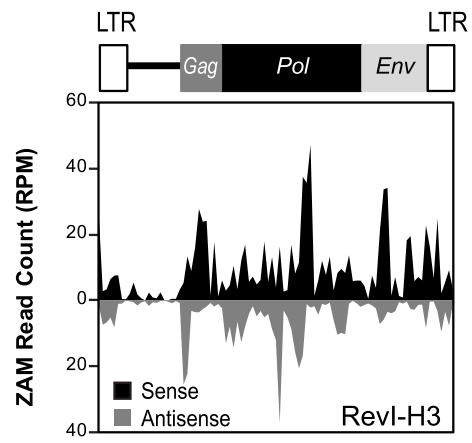

Fig. 6 ZAM is trapped in a germline piRNA cluster in all analyzed Rev lines. a, d Density profile of ZAM-derived piRNAs along the 8.4Kb ZAM sequence in the Revll-7 (a) and Revl-H3 (d) lines (allowing up to 3 mismatches). Sense and antisense reads are represented in black and grey, respectively. The organization of ZAM is displayed above the profiles. b, e Logo of nucleotide bias for the first ten positions of ZAM-derived piRNAs produced in Revll-7 (b) and Revl-H3 (e) ovaries. The nucleotide height represents its relative frequency at that position. $\mathbf{c}$, $\mathbf{f}$ Histogram showing the percentage of $5^{\prime}$-overlaps between sense and antisense ZAM-derived piRNAs (23-29 nt) in Revll-7 (c) and Revl-H3 (f) ovaries. The peak in red defines the 10-nt-overlapping pairs, and the Z-score is indicated

leaving the germline genome vulnerable to $Z A M$ invasion when its control is lost in somatic follicular cells. In agreement, the pGFP-ZAM sensor transgene was not silenced in the germline. This observation also reveals that antisense $Z A M$-derived piRNAs produced in somatic follicular cells are cell autonomous and do not transit to the germline to ensure $Z A M$ silencing in this compartment.

In fly ovaries, in addition to the piRNA pathway, the short interfering RNA (siRNA) pathway also is active and involved in TE silencing [32,33]. In addition, it has been reported that, during artificial horizontal transfers of the TE Penelope from D. virilis to D. melanogaster, only 21-nt siRNAs are detected in the ovary. However, they cannot completely silence Penelope which remained capable of occasional transposition [34]. In the case of
$Z A M$, the strong expression of the sensor transgene in the germline cells suggests that neither the siRNA pathway nor any other silencing pathway can silence this TE in the germline.

We previously showed that in the unstable RevI-H2 line in which $Z A M$ silencing is released in somatic follicular cells due to a deletion in flamenco, ZAM particles produced within follicular cells use the endosomal vitellogenin trafficking system, which is active during late oogenesis, to enter the closely apposed oocyte and invade the germline [23]. At the time of the invasion, no $Z A M$-derived piRNAs were produced in the germline. Therefore, this condition could be compared to what happens when a TE first enters a new species through horizontal transfer [35-38]. For instance, the P element was introduced from $D$. willistoni to $D$. melanogaster by 
horizontal transfer and a copy of $\mathrm{P}$ inserted at the subtelomeric heterochromatin $1 \mathrm{~A}$ site, which corresponds to a region that gives rise to multiple small RNAs [10, 38]. This insertion is sufficient to elicit a strong $\mathrm{P}$ repression in D. melanogaster P strains [39-41]. Studies on P-M dysgenic hybrid system showed that in the F1 hybrid adult females, the invading paternally inherited P element escapes silencing and mobilizes due to the absence of maternally deposited P-derived piRNAs. With age, fertility is restored and the $\mathrm{P}$ element is silenced suggesting also an adaptation to $P$ element transposon invasion. However, in contrast to what we observed for $Z A M$, Pderived piRNAs are produced from paternally inherited clusters [42, 43]. Our detailed analysis of piRNAs produced by the RevI-H2 ovaries revealed that this line adapted to $Z A M$ invasion by trapping a new $Z A M$ copy in a germline piRNA cluster, leading to the production of ZAM-derived piRNAs in the germline. Hence, the RevI-H2 line is the first example in which the germline, which does not have initially the genetic capacity to produce $Z A M$-derived piRNAs, needs to protect itself from invasion caused by the sudden loss of control of an endogenous somatic cell-specific TE, the expression of which is normally repressed and should not have been a risk for the progeny.

\section{Retention of invading somatic TEs in germline piRNA clusters protects the germline from further invasion}

In this study, we observed the de novo production of sense and antisense ZAM-derived piRNAs in RevI-H2 ovaries. Analysis of the ZMD and NZMD progenies showed that the piRNA cluster that trapped a ZAM copy was activated by maternal deposition of piRNAs other than ZAM-derived piRNAs. This finding strongly suggests that the $Z A M$ insertion occurred in an existing germline piRNA cluster. The specific features of these ZAM-derived piRNAs (10-nt overlap and $1 \mathrm{U}$ and 10A bias) indicate that they are produced through the germline-specific ping-pong cycle. Moreover, they successfully silenced the pGFP-ZAM sensor transgene in germline cells of RevI-H2 ovaries. As ZAM is not normally expressed in the germline, the sense transcripts, which are engaged in the ping-pong cycle and produce piRNAs, could arise (i) from a ZAM copy in a germline piRNA cluster, (ii) from dispersed $Z A M$ copies inserted in the vicinity of germline promoters, or (iii) from invading ZAM mRNAs produced from somatic cells.

Among the 142 piRNA clusters identified in the $D$. melanogaster genome, most of them are significantly enriched in pericentromeric and telomeric heterochromatin [9], regions that concentrate most TEs [44]. We previously proposed a model in which piRNA clusters play the role of TE traps [26]. This model relies on the capacity of TEs to transpose into piRNA clusters that passively acquire new TE content. Thus, TEs that "jump" into piRNA clusters can produce the corresponding piRNAs and silence homologous elements. This mechanism should constitute an adaptive advantage that can then be fixed by evolutionary selection. How piRNA clusters are formed and then produce piRNAs to repress a novel invasive TE is not well understood yet. Our findings indicate that de novo piRNAs can be produced by germline cells after $Z A M$ invasion from another cellular lineage (i.e., somatic follicular cells) and successfully counteract the invasion. This suggests that invasive TEs can be trapped by piRNA clusters. ZAM trapping into a pre-existing piRNA cluster could result from a random transposition event. However, we found that in all the Rev lines analyzed, a germline piRNA cluster trapped a ZAM copy. Therefore, TE trapping by piRNA clusters seems to be a frequent event, and/or there is selective pressure to maintain a newly inserted ZAM copy in a germline piRNA cluster. The chromatin structure or some physical constraints, such as the nuclear organization of piRNA clusters in the genome, may play a role in transposon trapping. It has been suggested that in Arabidopsis thaliana, a nuclear structure, termed KNOT, in which TE-enriched regions of all five chromosomes are entangled, is a preferential insertion site for TEs [45]. In addition, the low recombination rate of these heterochromatic regions might facilitate TE accumulation for further development into piRNA clusters [46].

\section{Conclusion}

In our model system, $Z A M$ internal invasion of the germline from another cell type mimics a TE horizontal transfer. This constitutes a unique opportunity to investigate the germline behavior after TE invasion in a system that experimentally imitates evolution. However, we cannot exclude that $Z A M$ silencing is progressive, thus requiring several generations for complete repression. Finally, it is thought that piRNA clusters allow germ cells to record the TEs to which they have been exposed to over time, resulting in their silencing by the piRNA pathway. For this reason, the content of all piRNA clusters could be considered as the genetic vaccination record of that fly line or population.

\section{Methods}

\section{Fly stocks, transgenic lines, and crosses}

All experiments were performed at $20^{\circ} \mathrm{C}$. The strains nanos-Gal4, actin-Gal4, $\mathrm{w}^{1118}$, $\mathrm{w}^{\mathrm{IR} 6}$, and the various Rev lines $[25,47]$ were from the GReD collection. The FM7c (\#2177) strain, the RNAi lines against white (\#35573), $A u b$ (\#35201), and AGO3 (\#35232) were from the Bloomington Drosophila Stock Center. The pGFP-ZAM sensor transgene (located on chromosome 2) was 
generated by inserting part of the $Z A M$ env region into the UASp-GFP vector containing FLP1 Recombination Target (FRT) sequences [48] after NotI/BamHI digestion. The ZAM env region was amplified by Taq polymerase using the primers 5'-GAAGCGGCCGCCGGGACTCACGACTGATGTG-3' and 5'-GAAGGATCCCGGAG GAATTGGTGGAGCGA-3'. The FRT-ZAM-FRT construct is in sense orientation relative to the GFP gene. Gal4-driven pGFP-ZAM sensor lines were established by crossing the pGFP-ZAM line with the actin-Gal4 or nanos-Gal4 driver lines.

\section{Immunofluorescence}

Ovaries from 3- to 5-day-old flies were dissected in Schneider's Drosophila Medium, fixed in $4 \%$ formaldehyde/PBT for $15 \mathrm{~min}$, rinsed three times with PBT $(\times 1$ PBS, $0.1 \%$ Triton, $1 \%$ BSA), and incubated in PBT for at least $1 \mathrm{~h}$ and then with goat anti-GFP (ab5450, Abcam; 1/1000), mouse anti-Ago3 (1/500) [9], or rabbit antiAub (1/500) [9] antibodies overnight. After 3 washes in PBT, ovaries were incubated with the corresponding secondary antibodies (1/1000), coupled to Alexa-488, Cy3, or Alexa-488, respectively, for $90 \mathrm{~min}$. After two washes, DNA was stained with the TOPRO-3 stain $(1 / 1000)$. Three-dimensional images were acquired on Leica SP5 and Leica SP8 confocal microscopes using a $\times 20$ objective and analyzed using the Fiji software [49]. Images of the progeny of $w^{\text {IR6 }}$ and Rev crosses were processed with the same parameters.

\section{Protein extraction and western blotting}

At least 5 pairs of ovaries from 3- to 5-day-old flies were dissected in $200 \mu \mathrm{l}$ of lysis buffer (17.5 mM HEPES, 1.3 $\mathrm{mM} \mathrm{MgCl} 2,0.38 \mathrm{M} \mathrm{NaCl}, 0.18 \mathrm{mM}$ EDTA, 22\% glycerol, $0.2 \%$ Tween-20, and protease inhibitor cocktail from Roche). After sonication, supernatants were recovered and $400 \mu \mathrm{g}$ of proteins were loaded on precast $4-15 \%$ acrylamide gels. Western blots were probed using antiGFP (Ozyme; \#JL-8; 1/1000) and anti-tubulin (to confirm equal loading) (Sigma, \#DM1A, 1/5000) antibodies, followed by an anti-mouse (Abliance; 1/1000) secondary antibody and then the Clarity Western ECL reagent (BioRad). Densitometric analysis was performed on nonsaturated signals using the Image Lab $^{\text {tx }}$ software (BioRad).

\section{Small RNA sequencing and bioinformatics analysis of piRNAs}

Total RNA was isolated from $80-100$ pairs of ovaries from 3- to 5-day-old flies or from ovarian somatic sheath (OSS) cell culture (for analysis of piRNA production by somatic follicular cells) with TRIzol Reagent (Ambion). After 2S RNA depletion, deep sequencing of 18-30-nt small RNAs was performed by Fasteris S.A.
(Geneva/CH) on an Illumina Hi-Seq 4000. Illumina small RNA-Seq reads were loaded into the small RNA pipeline sRNAPipe [50] for mapping to the various genomic sequence categories of the $D$. melanogaster genome (release 6.03). All libraries were normalized to the total number of genome-mapped reads (no mismatch). For the analysis, 23-29-nt RNAs were selected as piRNAs. All the analyses were performed using piRNAs mapped to TEs (0 to 3 mismatches) or genomeunique piRNAs mapped to piRNA clusters, as defined by [9] (no mismatch allowed), the strand relative to the transposon or the genome being determined [9]. The window size was of $428 \mathrm{nt}$ for flamenco, $91 \mathrm{nt}$ for $Z A M$, $80 \mathrm{nt}$ for Burdock, $87 \mathrm{nt}$ for Pifo, and $85 \mathrm{nt}$ for Phidippo to establish the density profile of piRNAs and dependent of the TE size. The ping-pong signature was assessed by counting the proportion of sense piRNAs with an overlap of $10 \mathrm{nt}$ with antisense piRNAs, based on piRNAs mapping to the analyzed TE (0 to 3 mismatches). The proportions of 1 - to 28-nt-long overlaps were determined, and the percentage of 10-nt overlaps defined as ping-pong signature. The $Z$-score was determined on the proportions of 1- to 23-nt-long overlaps and considered significant for values $>1.96$. The nucleotide frequency for each position within the 10-nt overlap was determined for the piRNAs mapping to the analyzed TE (0 to 3 mismatches) with ping-pong partners. Logos were generated with the WebLogo web server [51].

\section{Genome sequencing and analyses of new ZAM insertions in Revl-H2}

Genomic DNA from RevI-H2 was extracted from a sample of mixed sex adult flies using standard protocol. Input DNA was tagmented using the Illumina Nextera DNA sample preparation kit (Cat. No. FC-121-1030). Following a cleanup using the Zymo-Spin kit (Cat. No. D4023), the purified, tagmented DNA was then amplified via limited-cycle PCR that also added the indices (i7 and i5) and sequencing primers. AMPure XP beads (Cat. No. A63881) were then used to purify and size select the library DNAs. The libraries were then normalized to $2 \mathrm{nM}$ and pooled prior to cluster generation using a cBot instrument. The loaded flow cell was then pairedend sequenced $(2 \times 101 \mathrm{bp})$ on an Illumina HiSeq2500 instrument.

To identify new ZAM insertions in the RevI-H2 genome, we used two complementary approaches. First, we used the McClintock system which aims to identify nonreference TE insertions using multiple component TE detection systems (commit: 9f53a5b4e1fc977b22a77babfb24461face 407d3, options -m "popoolationte retroseq temp ngs_te_mapper te-locate"). Because McClintock component methods do not efficiently detect new TE insertions within repetitive regions, we developed a second 
approach to identify candidate TE insertions in piRNA clusters. Chimeric reads containing genomic sequence and $Z A M 5^{\prime}$ - or $3^{\prime}$-sequence were isolated from the unmappable reads. $Z A M$ sequences were then stripped off from these chimeric reads, and the resulting flanking sequences mapped to the $D$. melanogaster Release 6.03 genome. This approach identified a novel ZAM insertion in piRNA cluster 9 as defined by [30]. We validated the presence of the insertion by PCR on DNA extracted from RevI-H2 flies. The following primers were used for Additional file 1: Figure S4G: primer F $5^{\prime}$-CTCACCATTTCCTCCTTGAC-3' and primer $\mathrm{R}$ 5'-CTCCCAATCATCTCCTCCAA-3'. Sequencing of the amplicon was done by GATC Biotech.

\section{Additional files}

Additional file 1: Figure S1. The Revl-H2 line carries a deletion that removes ZAM from the flamenco piRNA cluster. Figure S2. In Revl-H2 ovaries, piRNAs derived from Burdock, the prototypic germinal TE, present similar features as those derived from ZAM. Figure S3. ZAM-derived piRNAs are de novo produced by the germline of Revl-H2 ovaries. Figure S4. ZAM-derived piRNAs originate from a germline piRNA cluster localized on the $X$ chromosome. Figure S5. Phidippo- and Pifo-derived piRNAs are mainly produced by the flamenco cluster. Figure S6. ZAM-derived piRNAs produced in the different Rev lines display similar features. (PDF 3179 kb)

Additional file 2: Review history. (DOCX $515 \mathrm{~kb}$ )

\section{Acknowledgements}

We thank Nathalie Guéguen, Françoise Pellissier, and Nadège Anglaret for the technical assistance. We thank Arpita Sarkar who constructed the plasmid PGFP-ZAM, Marion Delattre for the assistance sequencing the $w^{\operatorname{IR} 6}$ and Revl-H2 small RNA libraries, and J. Brennecke for Aub and AGO3 antibodies.

We thank all members of the team for discussion and critical comments.

\section{Review history}

The review history is available at Additional file 2.

\section{Authors' contributions}

$E B$ and $C D$ conceived the study. EB, CD, MY, and NM designed and performed the experiments. EB and CD gathered and analyzed the small RNA-Seq data. CD, EB, and SJ performed the bioinformatic analyses. CB and SJ gathered and analyzed the DNA-Seq data. EB and CD analyzed the data. SJ and CV participated in the discussions about the project and critically read the manuscript. CD and EB wrote the article. All authors read and approved the final manuscript.

\section{Funding}

This work was supported by grants from the Agence Nationale pour la Recherche (ANR-PlasTiSiPi and ANR-EpiTET projects). N.M and M.Y were supported by the Ministère de l'Enseignement Supérieur et de la Recherche (MESR) and the Ligue contre le Cancer. E.B received a grant from the Region Auvergne. This research is supported by the University of Georgia Research Foundation and the French government IDEX-ISITE initiative 16-IDEX-0001 (CAP20-25).

\section{Availability of data and materials}

RNA-Seq (SRR7651646, OSS cell culture; SRR7630522, ovaries from 3- to 5day-old W'R6 flies; SRR7630528, ovaries from 3- to 5-day-old Revl-H2 flies; SRR7630524, ovaries from 3- to 5-day-old Revll-7 flies; SRR7630523, ovaries from 3- to 5-day-old RevI-H3 flies; SRR7630525, early embryos from 3- to 5day-old Revl-H2 flies; SRR7630526, ovaries from 3- to 5-day-old F1 flies from a cross between a $w^{\mathbb{I R} 6}$ female and a control line harboring the PGFP-ZAM transgene whose expression is driven by the nanos-Gal4 driver; SRR7630527, ovaries from 3- to 5-day-old F1 flies from a cross between a Revl-H2 female and a control line harboring the PGFP-ZAM transgene whose expression is driven by the nanos-Gal4 driver) and DNA-Seq from Revl-H2 (SRR8975035) datasets supporting the conclusions of this article are available in the SRA repository under accession number SRP155919 [52].

Ethics approval and consent to participate

Not applicable.

\section{Consent for publication}

Not applicable.

\section{Competing interests}

The authors declare that they have no competing interests.

\section{Author details}

'GReD, Université Clermont Auvergne, CNRS, INSERM, Faculté de Médecine, 63000 Clermont-Ferrand, France. ${ }^{2}$ Present address: UFIP UMR-CNRS 6286, Epigénétique: prolifération et différenciation, Faculté des Sciences et des Techniques, 2 rue de la Houssinière, 44322 Nantes, France. ${ }^{3}$ Department of Genetics and Institute of Bioinformatics, University of Georgia, $120 \mathrm{E}$. Green St, Athens, GA 30602, USA.

Received: 2 January 2019 Accepted: 11 June 2019

Published online: 21 June 2019

\section{References}

1. Hancks DC, Kazazian HH. Roles for retrotransposon insertions in human disease. Mobile DNA. 2016;7:9.

2. Levin HL, Moran JV. Dynamic interactions between transposable elements and their hosts. Nat Rev Genet. 2011;12:615-27.

3. Slotkin RK, Martienssen R. Transposable elements and the epigenetic regulation of the genome. Nat Rev Genet. 2007;8:272-85.

4. Aravin A, Gaidatzis D, Pfeffer S, Lagos-Quintana M, Landgraf P, lovino N, et al. A novel class of small RNAs bind to MILI protein in mouse testes. Nat Cell Biol. 2006:442(7099):203-7.

5. Girard A, Sachidanandam R, Hannon GJ, Carmell MA. A germlinespecific class of small RNAs binds mammalian Piwi proteins. Nature. 2006;442:199-202.

6. Grivna ST, Pyhtila B, Lin H. MIVI associates with translational machinery and PIWl-interacting RNAs (piRNAs) in regulating spermatogenesis. Proc Natl Acad Sci U S A. 2006;103:13415-20.

7. Lau NC, Seto AG, Kim J, Kuramochi-Miyagawa S, Nakano T, Bartel DP, et al. Characterization of the piRNA complex from rat testes. Science. 2006;313: 363-7.

8. King RC, Aggarwal SK, Aggarwal U. The development of the female Drosophila reproductive system. J. Morphol. 1968;124:143-66.

9. Brennecke J, Aravin AA, Stark A, Dus M, Kellis M, Sachidanandam R, et al. Discrete small RNA-generating loci as master regulators of transposon activity in Drosophila. Cell. 2007;128:1089-103.

10. Senti K-A, Brennecke J. The piRNA pathway: a fly's perspective on the guardian of the genome. Trends Genet. 2010;26:499-509.

11. Siomi MC, Sato K, Pezic D, Aravin AA. PIWl-interacting small RNAs: the vanguard of genome defence. Nat Rev Mol Cell Biol. 2011;12:246-58.

12. Sienski $G$, Dönertas $D$, Brennecke J. Transcriptional silencing of transposons by Piwi and Maelstrom and its impact on chromatin state and gene expression. Cell. 2012;151:964-80.

13. Gunawardane LS1, Saito K, Nishida KM, Miyoshi K, Kawamura Y, Nagami T, Siomi H, Siomi MC. A slicer-mediated mechanism for repeat-associated siRNA 5' end formation in Drosophila. Science. 2007; 315(5818):1587-1590.

14. Brennecke J, Malone CD, Aravin AA, Sachidanandam R, Stark A, Hannon GJ. An epigenetic role for maternally inherited piRNAs in transposon silencing supplementary data. Science. 2008;322:1387-92.

15. Le Thomas A, Stuwe E, Li S, Du J, Marinov G, Rozhkov N, et al. Transgenerationally inherited piRNAs trigger piRNA biogenesis by changing the chromatin of piRNA clusters and inducing precursor processing. Genes \& Development. 2014;28:1667-80.

16. de Vanssay A, Bougé A-L, Boivin A, Hermant C, Teysset L, Delmarre V, et al. Paramutation in Drosophila linked to emergence of a piRNA-producing locus. Nature. 2012;490:112-5. 
17. Malone CD, Brennecke J, Dus M, Stark A, McCombie WR, Sachidanandam R, et al. Specialized piRNA pathways act in germline and somatic tissues of the Drosophila ovary. Cell. 2009;137:522-35.

18. Li C, Vagin W, Lee S, Xu J, Ma S, Xi H, et al. Collapse of germline piRNAs in the absence of Argonaute3 reveals somatic piRNAs in flies. Cell. 2009;137:509-21.

19. Pelisson A, Song SU, Prud'homme N, Smith PA, Bucheton A, Corces VG. Gypsy transposition correlates with the production of a retroviral envelopelike protein under the tissue-specific control of the Drosophila flamenco gene. EMBO J. 1994;13:4401-11.

20. Prud'homme N, Gans M, Masson M, Terzian C, Bucheton A. Flamenco, a gene controlling the gypsy retrovirus of Drosophila melanogaster. Genetics. 1995;139(2):697-711.

21. Desset S, Meignin C, Dastugue B, Vaury C. COM, a heterochromatic locus governing the control of independent endogenous retroviruses from Drosophila melanogaster. Genetics. 2003;164:501-9.

22. Chalvet F, Teysset L, Terzian C, Prud'homme N, Santamaria P, Bucheton A, et al. Proviral amplification of the Gypsy endogenous retrovirus of Drosophila melanogaster involves env-independent invasion of the female germline. EMBO J. 1999;18:2659-69.

23. Brasset E, Taddei AR, Arnaud F, Faye B, Fausto AM, Mazzini M, et al. Viral particles of the endogenous retrovirus ZAM from Drosophila melanogaster use a pre-existing endosome/exosome pathway for transfer to the oocyte. Retrovirology. 2006;3:25.

24. Leblanc $P$, Desset $S$, Dastugue B, Vaury C. Invertebrate retroviruses: ZAM a new candidate in D.melanogaster. EMBO J. 1997;16:7521-31.

25. Desset S, Conte C, Dimitri P, Calco V, Dastugue B, Vaury C. Mobilization of two retroelements, ZAM and Idefix, in a novel unstable line of Drosophila melanogaster. Mol Biol Evol. 1999;16:54-66.

26. Zanni V, Eymery A, Coiffet M, Zytnicki M, Luyten I, Quesneville H, et al. Distribution, evolution, and diversity of retrotransposons at the flamenco locus reflect the regulatory properties of piRNA clusters. Proc Natl Acad Sci U S A. 2013;110:19842-7.

27. Desset S, Buchon N, Meignin C, Coiffet M, Vaury C. In Drosophila melanogaster the COM Locus Directs the Somatic Silencing of Two Retrotransposons through both Piwi-Dependent and -Independent Pathways. PLoS One. 2008;3(2):e1526.

28. Mevel-Ninio M, Pelisson A, Kinder J, Campos AR, Bucheton A. The flamenco locus controls the gypsy and ZAM retroviruses and is required for Drosophila oogenesis. Genetics. 2007;175:1615-24.

29. Nelson MG, Linheiro RS, Bergman CM. McClintock: an integrated pipeline for detecting transposable element insertions in whole-genome shotgun sequencing data. G3 (Bethesda). 2017;7:2763-78.

30. George P, Jensen S, Pogorelcnik R, Lee J, Xing Y, Brasset E, et al. Increased production of piRNAs from euchromatic clusters and genes in Anopheles gambiae compared with Drosophila melanogaster. Epigenetics \& Chromatin. 2015:8:50.

31. Goriaux C, Théron E, Brasset E, Vaury C. History of the discovery of a master locus producing piRNAs: the flamenco/COM locus in Drosophila melanogaster. Front. Gene. 2014;5:257.

32. Czech B, Malone CD, Zhou R, Stark A, Schlingeheyde C, Dus M, et al. An endogenous small interfering RNA pathway in Drosophila. Nature. 2008;453: 798-802.

33. Kawamura Y, Saito K, Kin T, Ono Y, Asai K, Sunohara T, et al. Drosophila endogenous small RNAs bind to Argonaute 2 in somatic cells. Nature. 2008; 453:793-7.

34. Rozhkov NV, Aravin AA, Zelentsova ES, Schostak NG, Sachidanandam R, McCombie WR, et al. Small RNA-based silencing strategies for transposons in the process of invading Drosophila species. RNA. 2010;16:1634-45.

35. Panaud O. Horizontal transfers of transposable elements in eukaryotes: The flying genes. C. R. Biol. 2016;339:296-9.

36. Baidouri El M, Carpentier M-C, Cooke R, Gao D, Lasserre E, Llauro C, et al. Widespread and frequent horizontal transfers of transposable elements in plants. Genome Res. 2014;24:831-8.

37. Barckmann B, El-Barouk M, Pelisson A, Mugat B, Li B, Franckhauser C, et al. The somatic piRNA pathway controls germline transposition over generations. Nucleic Acids Res. 2018;46:9524-36.

38. Daniels SB, Peterson KR, Strausbaugh LD, Kidwell MG, Chovnick A. Evidence for horizontal transmission of the P transposable element between Drosophila species. Genetics. Genetics. 1990;124:339-55.
39. Ronsseray S, Lehmann M, Anxolabéhère D. Copy number and distribution of $\mathrm{P}$ and I mobile elements in Drosophila melanogaster populations. Chromosoma. 1989;98:207-14.

40. Marin L, Lehmann $M$, Nouaud $D$, Izaabel $H$, Anxolabéhère $D$, Ronsseray S. PElement repression in Drosophila melanogaster by a naturally occurring defective telomeric P copy. Genetics. 2000;155:1841-54.

41. Brennecke J, Malone CD, Aravin AA, Sachidanandam R, Stark A, Hannon GJ. An epigenetic role for maternally inherited piRNAs in transposon silencing. Science. 2008;322:1387-92.

42. Khurana JS, Wang J, Xu J, Koppetsch BS, Thomson TC, Nowosielska A, et al. Adaptation to $\mathrm{P}$ element transposon invasion in Drosophila melanogaster. Cell. 2011;147:1551-63.

43. Moon S, Cassani M, Lin YA, Wang L, Dou K, Zhang ZZ. A robust transposonendogenizing response from germline stem cells. Developmental Cell. 2018; 47:660-71.

44. Bergman CM, Quesneville $H$, Anxolabéhère D, Ashburner M. Recurrent insertion and duplication generate networks of transposable element sequences in the Drosophila melanogaster genome. Genome Biol. 2006; 7(11):R112.

45. Grob S, Schmid MW, Grossniklaus U. Hi-C analysis in Arabidopsis identifies the KNOT, a structure with similarities to the flamenco locus of Drosophila. Mol Cell. 2014;55:678-93.

46. Lu J, Clark AG. Population dynamics of PIWI-interacting RNAs (piRNAs) and their targets in Drosophila. Genome Res. 2010;20:212-27.

47. Leblanc P, Desset $S$, Dastugue B, Vaury C. Invertebrate retroviruses: ZAM a new candidate in D. melanogaster. EMBO J. 1997;16:7521-31.

48. Dufourt J, Dennis C, Boivin A, Gueguen N, Theron E, Goriaux C, et al. Spatiotemporal requirements for transposable element piRNA-mediated silencing during Drosophila oogenesis. Nucleic Acids Res. 2014;42:2512-24.

49. Schindelin J, Arganda-Carreras I, Frise E, Kaynig V, Longair M, Pietzsch T, et al. Fiji: an open-source platform for biological-image analysis. Nat Meth. 2012;9:676-82.

50. Pogorelcnik R, Vaury C, Pouchin P, Jensen S, Brasset E. sRNAPipe: a Galaxybased pipeline for bioinformatic in-depth exploration of small RNAseq data. Mobile DNA. 2018;9:25.

51. Crooks GE, Hon G, Chandonia J-M, Brenner SE. WebLogo: a sequence logo generator. Genome Res. 2004;14:1188-90.

52. Duc C, Yoth M, Jensen S, Mouniée N, Bergman CM, Vaury C, Brasset E. Trapping a somatic endogenous retrovirus into a germline piRNA cluster immunizes the germline against further invasion. Data sets. SRA. 2019. https://www.ncbi.nlm.nih.gov/sra/SRP155919

\section{Publisher's Note}

Springer Nature remains neutral with regard to jurisdictional claims in published maps and institutional affiliations.

Ready to submit your research? Choose BMC and benefit from:

- fast, convenient online submission

- thorough peer review by experienced researchers in your field

- rapid publication on acceptance

- support for research data, including large and complex data types

- gold Open Access which fosters wider collaboration and increased citations

- maximum visibility for your research: over $100 \mathrm{M}$ website views per year

At $\mathrm{BMC}$, research is always in progress.

Learn more biomedcentral.com/submissions 